\title{
PRÁTICAS DOCENTES NO RECIFE E OLINDA NA SEGUNDA METADE DO SÉCULO XIX
}

\author{
Dayana Raquel Pereira de Lima* \\ Yan Soares Santos**
}

\begin{abstract}
RESUMO: A leitura, transcrição e sistematização das fontes governamentais relativas ao trabalho e associações docentes no Recife e Olinda, no século XIX, desvelaram práticas vinculadas, majoritariamente, a benesses individuais e ganhos políticos em suas relações com os poderes públicos. Ao rastrearmos, especificamente, as trajetórias e demandas dos membros da Sociedade Propagadora da Instrução Pública de 1872, bem como as petições feitas pelos professores aos poderes públicos dos principais expedientes práticos do trabalho docente salários, gratificações, permutas, licenças médicas, transferências, materiais didáticos etc- argumentaremos,através da metodologia da microanálise (REVEL, 1998),que a docência como categoria profissional foi marcada por práticas individuais de cidadania, isto é, embora houvesse a existência de associações, de "interesse comuns" e um "desconforto" de professores públicos, estes desenvolviam estratégias pessoais, de acordo com privilégios conquistados ao longo da carreira, os quais, na prática, afastavam-se de constituírem uma identidade docente.

PALAVRAS-CHAVE: Associação de professores; Trabalho docente; Século XIX.
\end{abstract}

\section{Practical teachers in Recife and Olinda in second half XIX century}

RESUME: The reading, transcription and systemisation of governmental sources related to work and teaching associations in Recife and Olinda, during the XIX century, revealed practices linked mainly to individual benefits and political gains in its relations with public power. When tracking the specific path and demands of members of the 1872 Sociedade Propagadora da Instrução Pública as well as the petitions done by the teachers to the public power in the main working shifts of teaching - salaries, gratifications, exchanges, medical licenses, transferences, educational material etc - we will argue, using the methodology of microanalysis (REVEL, 1998), that the teachers as a working category was marked by individual practices of citizenship. In this sense, although there were associations, of "common interests" and a "discomfort" of public teachers, those developed personal strategies, according to the privileges acquired along their career which in fact deviate from building a teacher identity.

KEYWORDS: Teachers Association; Teaching work; XIX Century.

\section{Prácticas docentes en Recife y Olinda en la segunda mitad del siglo XIX}

RESUMEN: La lectura, la transcripción y la sistematización de las fuentes gubernamentales para el trabajo y para las asociaciones docentes en Recife y Olinda, en el siglo XIX, presentaron prácticas asociadas, en su gran mayoría, a favores individuales y a beneficios políticos en sus relaciones con las autoridades públicas. Al rastrear, específicamente, las trayectorias y las demandas de los miembros de la Sociedade Propagadora da Instrução Pública de 1872, así como las peticiones realizadas por los maestros a las autoridades públicas de los principales expedientes prácticos del trabajo docente - sueldos, gratificaciones, intercambios, licencias por enfermedad, transferencias, materiales de enseñanza, etc. - vamos a argumentar, utilizando la metodología de microanálisis (REVEL, 1998), que la docencia como categoría profesional estuvo marcada por las prácticas individuales de ciudadanía, es decir, aunque hubo asociaciones de "intereses comunes" y un "malestar" de los maestros de las escuelas públicas, estos desarrollaron estrategias personales, de acuerdo con los privilegios conquistados a lo largo de su carrera, que en la práctica, se alejaban de la constitución de una identidad docente.

PALABRAS CLAVE: Asociación de maestros; Trabajo docente; Siglo XIX.

*Doutoranda em Educação pela Universidade Federal de Pernambuco. Email: daylima27@gmail.com.

**Doutorando em Educação pela Universidade Federal de Pernambuco. pernambucoyan.ssantos27@gmail.com. 


\section{Introdução}

Os estudos sobre o processo de estatização escolar em Portugal mencionam como a profissionalização do professor esteve imbricada com o próprio processo sócio-histórico de mudança do estatuto docente. A passagem da forma de ensino artesanal do mestre-escola baseada na "aprendizagem pela prática", no século XVIII, para o trabalho dos professores primários, no século XIX, com a introdução de mecanismos mais rígidos de seleção e de recrutamento do professorado, com a introdução de novos saberes direcionados à qualidade do ensino (pedagogia e psicologia), com instituições (Escolas Normais) voltadas diretamente à produção de um saber científico, legitimado pelas questões do ensino; com a constituição de associações docentes preocupadas em discutir os diferentes aspectos do exercício da profissão, consolidaram a funcionarização docente. Os professores tornaram-se a "voz" dos novos dispositivos de escolarização, por isso, o Estado não mediu forças em acelerar o processo de profissionalização da docência, progressivamente, viabilizando o professor como funcionário público (NÓVOA, 1991 e 1992).

Conforme afirmou Heloísa Vilella (2000), o que mudou fundamentalmente a partir da década de 1870 foi o próprio estatuto da profissão docente que seria marcado pela conquista da forma escolar moderna em detrimento de outras mais antigas. Esse processo se deu na passagem de uma educação menos sistemática, com a função docente ainda acessória e não especializada, para outro momento caracterizado por um conjunto de saberes, normas e valores próprios da atividade docente que passam a definir a ação dos professores.

Em consonância com a conquista da forma escolar, houve a produção do discurso em torno da defesa das prerrogativas do ofício docente, buscando a conquista da autonomia por meio da participação, como os movimentos associativos. Havia um duplo movimento: dos professores com os poderes hegemônicos, tentando enquadrá-los aos seus objetivos políticos, e dos professores com os professores, pais e alunos, articulando-se num grupo com objetivos comuns. A busca de uma identidade profissional, no final do século XIX, talvez tenha sido a maior descontinuidade entre o velho mestre-escola e o novo professor primário ou a nova professora (VILLELA, 2000).

Ao longo do século XIX, consolida-se a imagem do professor no entremeio do sacerdócio e da humildade, da competência de ensino (sobretudo por meio da licença para ensinar) e dos desafios práticos impostos na sala de aula, da criação de instituições destinadas à formação docente, da paulatina substituição do ensino dirigido por religiosos para um ensino laico, ao sofrer intervenções e enquadramento do Estado. O processo de 
funcionarizaçãolestatização da docência não se deu de forma unilateral (com o Estado impondo regras e os professores acatando-as), muito menos se concretizou, na prática, pela simples reprodução dos ideais das classes dirigentes. $\mathrm{O}$ processo de funcionarização/estatização se deu num complexo fazer-se (THOMPSON, 1987)dos sujeitos e grupos envolvidos na dinâmica educacional, mediante uma consciência das escolhas e ações, encarnadas pelos valores, tradições e ideias em contextos plurais.

Com base nesses apontamentos, não comungaremos de estudos que trabalham com as categorias profissionalização e identidade docente, emergidas das discussões a partir de meados da década de 1980 do século passado. Consideramos cometer um anacronismo em sua utilização na abordagem do século XIX (SILVA, 2014). As pesquisas ancoradas nessas categorias consideram componentes fundamentais na construção da identidade docente a existência de um conjunto de "saberes" específicos à docência adquiridos para o e durante o exercício do seu trabalho (TARDIF \& LESSARD, 2014; NÓVOA, 1992 e 2000; VILELLA, 2000).

A concepção de identidade docente advém dos estudos do final do século $\mathrm{XX}$, os quais, de maneira geral, entendem a profissão docente ancorada em três pilares centrais: aprendizagem profissional, ativismo docente e desenvolvimento pessoal. Aprendizagem profissional, mediante a apropriação dos saberes de que os professores são portadores, sobretudo, por meio da formação profissional. Ativismo docente, pois o processo identitário passa também pela capacidade de exercer a autonomia na atividade docente. E desenvolvimento pessoal, em se tratando de como a maneira do professor ensinar desvenda a maneira de ser, a indissociabilidade entre o eu profissional e o eu pessoal (NÓVOA, 2000).

No entanto, o exercício da docência, no século XIX, alicerçou-se "mais na educação dos sentidos, dos hábitos, das condutas e regras (os segredos) do ofício do que lições registradas em livros, manuais ou textos especializados" (GONDRA \& SCHUELER, 2008, p. 194).

Basta observarmos os rastros deixados pelas petições dos(as) professores(as) primários(as), com a finalidade de conseguir alguma vantagem individual (estabelecidas em lei) ou não, remetidas às autoridades da Instrução Pública em Pernambuco e em outras partes do Império, ao longo do XIX, para entendermos que, em alguns casos, as aprovações de tais petições se relacionavam mais com os privilégios patronais e clientelistas envolvidos (e estruturantes da sociedade imperial) do que com a formalização legal (GARCIA, 2003 e 2004; GONDRA, 2001; LIMA, 2014; SCHUELER, 2002; SILVA, 2006). 
Com relação a Pernambuco, o trabalho de Adriana Silva argumenta que os docentes públicos atuantes na província estiveram na linha de frente, juntamente com as famílias e os políticos da terra, construindo as práticas de escolarização provinciais e, ao mesmo tempo, definindo os componentes técnicos, políticos e pedagógicos constitutivos da docência no período. Os professores públicos, naquela ocasião, estiveram tensionados entre a sua necessidade de sobrevivência e as difíceis condições materiais e políticas reais para o exercício do ofício (SILVA, 2006, p. 149-267).

Somados aos tensionamentos e conflitos da docência estavam os seus "riscos", cujas consequências incidiam diretamente na organização da instrução primária. Em Pernambuco, ao longo do século XIX, (embora ainda não existam trabalhos que abordem a temática com profundidade para a primeira metade do século XIX) o afastamento dos professores do exercício de seu trabalho, causavam "desconfortos" entre os sujeitos envolvidos. Os professores, por demonstrarem nas fontes, de múltiplas formas, uma necessidade imperiosa de se afastarem da docência por um tempo; as autoridades públicas em relação à aprovação ou não dos afastamentos dos professores e, em relação a como ficariam organizadas as aulas após o afastamento; e os pais de famílias, os quais em certos casos exigiam a substituição ou a volta do professor afastado (LIMA, 2014).

Diante da conjuntura mencionada, suspeitamos que os registros de petições dos expedientes práticos feitos pelos(as) professores(as) públicos(as) e as várias formas de aprovação dos mesmos (ordenados, gratificações, licenças médias, transferências, materiais didáticos, permutas, multas, discussões de métodos de ensino, dentro outros), as práticas de associativismo, em específico, a da Sociedade Propagadora de Instrução Pública de 1872 e o "desconforto" dos professores públicos, constituíram a docência como categoria profissional marcada por práticas individuais de cidadania, isto é, embora houvesse a existência de grupos docentes, estes desenvolviam estratégias pessoais, de acordo com privilégios conquistados ao longo da carreira, os quais, na prática,afastavam-se de uma identidade docente.

As categorias teórico-metodológicas escolhidas neste artigo despertarão nosso interesse - ao investigar as fontes relativas à educação e instrução no Recife do século XIX pelas descontinuidades das práticas de escolarização, pela heterogeneidade das escolhas, certezas, incertezas e comportamentos observados dos sujeitos numa pluralidade de contextos e diante de estruturas preexistentes aos mesmos. Trata-se de empreender uma visão crítica dos instrumentos e procedimentos de análise, sem dicotomias entre macro/micro, sujeito/objeto, práticas/discursos, grupo/indivíduo, com o intuito de deslocarmos o "olhar" às relações de 
trabalho permeadas por experiências vividas no cotidiano urbano (THOMPSON, 1987a), fundamentos de uma experimentação narrativa que se aproxima da chamada "MicroHistória" (REVEL, 1998, p. 29-30).

\section{Práticas associativas voltadasà cidadania}

No cerne da discussão sobre a trajetória dos operários, alguns historiadores da década de 1980 passaram a compilar documentações importantes capazes de ampliar a dimensão dos estudos sobre os trabalhadores/operários. Mais preocupados com temas clássicos ou não da historiografia do trabalho, as produções focam, majoritariamente, assuntos como a "formação de classe, lutas nos locais de trabalho, movimento operário, sindicatos e correspondentes orientações ideológicas, ações coletivas, relações com o Estado, ideologia estatal e empresarial, formas de organização da produção e gestão da força de trabalho" (SILVA, 2003, p. 22). Dito isto, houve a necessidade de redimensionar as análises dos trabalhadores por óticas diferentes.

A partir de 1979, as pesquisas redimensionaram a análise dos trabalhadores através da busca das experiências historicamente constituídase implicações para suas ações enquanto trabalhador (BATALHA, 2004). A condição do operário era diversa. Porém, acreditamos num longo século XIX brasileiro, no qual, as relações de trabalho sofreram lentas modernizações e transformações, porém, não houve mudança com relação a compreensão da categoria trabalhador (HOBSBAWM, 1995; EISENBERG, 1977).

A História Social do Trabalho da década de 1860 encontrou escopo nos estudos do teórico inglês, Edward Palmer Thompson (1987a, 1987b, 1987c), relativos à história da formação da classe operária da Inglaterra, atualmente, base teórica central na maioriadas pesquisas em história social do trabalho. Destaca-se o pioneirismo em compreenderos múltiplos pontos de vistas da vida do operário a fim de compreender como ele se comportava dentro e fora das fábricas.

Interessado nas práticas dos trabalhadores "fora das fábricas", o historiador britânico tece seu argumento através de ampla pesquisa sobre a vida social e cultural do trabalhador inglês em finais do século XVIII e início dos XIX. Seu principal argumento é o fato da classe operária inglesa só se formar enquanto classe quando se compreende enquanto classe. A classe é antes de tudo um devir histórico, e não se pode fugir às vicissitudes do tempo. São as vicissitudes, ou seja, o que é vivenciado por eles no exercício de seu ofício e fora dele que vai moldando-o e o meio em que vive influencia na sua consciência de relação de classe. Ou seja, 
a experiência para Thompson é vivenciada duplamente por eles. Primeiro, (1) há a experiência de classe, aquela na qual o trabalhador está inserido pelo próprio condicionamento de sua relação com os meios de produção econômicos, na medida em que tais experiências são vividas e interpretadas pelo trabalhador (2) o trabalhadoras relações com os meios de produção em experiência consciente da classe (consciência) e compreende-se junto a seus pares (THOMPSON, 1987a).

Nesta linha de raciocínio, o operário não é produto inequívoco da indústria, mas, o sistema industrial um produto da relação entre o trabalhador e a nova forma de organização da produção a partir da Revolução Industrial. Ou seja, o operário (classe operária) é um eterno devir, um fazer-se em meio a circunstâncias diárias. A partir da pesquisa e análise de como os trabalhadores experienciavam suas trajetórias, permite-nos compreender suas ações em prol de objetivos comuns a seus pares, na organização de associações de ofício, por meio da greve, petições públicas e a instrução de seus colegas (THOMPSON, 1987a; 1987b; 1987c). Para nós, a pesquisa sobre a experiência dos sujeitos insere-se na perspectiva da "vista de baixo", preocupada com o microscópico (capilar) das relações.

O estudo sobre o associativismo volta-seàs práticas coletivas de ação política/social executada pelos trabalhadores ao longo do século XIX e compreende o fazer-se do trabalhador. É um campo de pesquisa que, cada vez mais, agrega adeptos ao longo dos anos, ampliando as pesquisas aos aspectos da vida dos sujeitos associados e do gênero dessas associações. Podemos afirmar, de forma geral, que o "fenômeno" associativista tenha sido descendente dos debates gestados no Iluminismo, período no qual as associações foram idealizadas para reunir pessoas atuantes com interesses comuns em busca de uma ideia de civilização e progresso. Os burgueses tinham seus interesses comuns a serem representados politicamente quando o assunto era o comércio, a indústria, a agricultura. Atentos a essa investida, os trabalhadores também enxergaram no associativismo uma forma de fortalecimento de suas estratégias de proteção e organização profissional. Os trabalhadores, paulatinamente, tomaram para si a estratégia das elites letradas e se preocuparam em associarem-se e instruírem-se em busca de lutas por demandas comuns (MAC CORD \& BATALHA, 2014).

As associações de trabalhadores procuraram, ao longo do século XIX,delimitar suas ações em prol de seus pares. Cada trabalhador de ofício parecia ter uma associação que o representasse. Com o pagamento de taxas mensais os sócios teriam assegurado mutualmente apesar das diversas maneiras em proteger seus membros- a possibilidade de ter atendimento 
médico, auxílio financeiro em caso de doença capaz de afastá-lo do trabalho, auxílio financeiro se estivesse desempregado e ainda uma subvenção à sua esposa caso ela ficasse viúva. Além dessa proteção mais pessoal ao trabalhador, as associações de ofício tinham enquanto empreitada a proteção do mercado de trabalho e a luta por direitos destinados aos pares. Pesquisas demonstram como as associações pugnavam pelo direito dos associados perante o governo, além de construírem relações verticais e horizontais na sociedade e política.

As pesquisas demonstram também uma questão intrigante que precisa ser evidenciada. As associações de ofício, por mais que procurasse todas essas questões não foram capazes de homogeneizar o movimento dos trabalhadores no Brasil, no decorrer do século XIX. Os ofícios de caixeiros, por exemplo, diferenciavam-se em suas associações (caixeiros de hotéis eram considerados como "outro tipo de caixeiro" e tinham uma outra associação), do mesmo modo como os trabalhadores de ofícios urbanos e artífices também só se engajavam com a luta dos trabalhadores de fábricas enquanto aquilo lhes fosse benéfico. Assim, destacamos a fluidez e a dinâmica dessa experiência de classe thompsoniana de consciente pertencimento a um lugar social comum (MAC CORD, 2012; SANTOS, 2014; MAC CORD \& BATALHA, 2014).

Cruzando a bibliografia especializada com as fontes, adentramos ao emaranhado de algumas associações do Recife na Província de Pernambuco ao longo do século XIX. A Associação dos Empregados no Comércio de Pernambuco é um exemplo importante sobre o associativismo, na medida em que houve a busca particular por instrução profissional e negociação com o poder público em Pernambuco, conforme interesse destacado em seu estatuto de 1892, "reunir em um grêmio fraternal os empregados no mesmo comércio protegêlos e as suas famílias, instruí-los e pugnar pelos interesses legítimos de cada um deles e pelos da classe em geral, empregando os recursos a seu alcance."1. Havia o interesse dos associados usar a associação como meio para auxílios políticos objetivos, onde pugnar (leia-se: tomar a defesa) pelos interesses legítimos representava uma objetividade não apenas particular a um dos associados, masda classe em geral.

Outra associação foi a União Beneficente dos Caixeiros de Hotéis, cujos estatutosprocurava garantir que a classe dos caixeiros de hotéis constituísse uma só família. Além de garantirem a defesados seus associados, caso fossem vítimas de prisões, perseguições ou injustiças por parte de seus patrões, depois de estudado e resolvido o caso em 
sessão social. E, finalmente, financiaram uma biblioteca para a instrução de seus associados, bem como um curso de ensino para os mesmos ${ }^{2}$.

Percebemos aqui uma relação de disputa entre os caixeiros associados na Associação dos Empregados do Comércio em Pernambuco e a União Beneficente dos Caixeiros de Hotéis. Havia algum contexto de distinção entre esses caixeiros. Eles não se compreendiam enquanto trabalhadores do mesmo ofício (caixeiro), muito menos participantes de um mesmo processo de acesso aos bens de produção (trabalhadores).

Outro caso consistiuna Corporação Operária de Camaragibe, fundada em 1903, especificando a criação dos Conselhos Profissionais para Homens e Senhoras. Os principais objetivos dessa entidade prezavam por: manter os operários com contato direto com o chefe; velar por acidentes; comodidade e bem-estar da Fábrica; cuidar da aprendizagem sendo esta levada à altura da verdadeira Formação Profissional completa, conferindo diplomas de habilitação. Essa associação foi fundada numa relação intrínseca entre o dono da Fábrica de Camaragibe, o Carlos Alberto de Menezes e os seus trabalhadores. Percebemos que houve uma diferença entre este tipo de associação e as demais faladas anteriormente. Nesta, existiu o associativismo católico. O catolicismo através da Encíclica Rerum Novarum dirimiu instruções acerca da questão operária no mundo, incentivando a abertura de associações católicas para vincular os trabalhadores das fábricas e com isso trabalharem em conjunto com seus patrões,objetivando o desenvolvimento civilizado, voltado ao progresso da indústria.

Por último, e não menos importante, destacamos o papel da Sociedade dos Artistas Mecânicos e Liberais (SAML), atuante no Recife desde a proibição das corporações de ofício em 1824. A Associação de mestres carpinteiros e carapinas surgiu como Confraria da Igreja de São José de Ribamar, localizada no Bairro de São José, em 1836. Os associados possuíam dois objetivos centrais: o primeiro era o "aperfeiçoamento" mais amplo dos associados, ou seja, a instrução para o ofício; e o segundo, incrementar as práticas de auxílio mútuo (MAC CORD, 2013).

Ou seja, os trabalhadores de ofício da SAML não demonstraram, em nenhum documento pesquisado, possuir alguma relação com a da Corporação da Fábrica Camaragibe. A questão desta última associação é diferente, mas, substancial para a compreensão (ou pelo menos proposição) de que os trabalhadores de ofício urbanos não tinham uma relação próxima com os trabalhadores das fábricas - muito menos entre si (trabalhadores urbanos com trabalhadores urbanos). Portanto, como já mencionado pela bibliografia especializada no movimento associativista e, a partir dos casos ocorridos na cidade do Recife, percebemos uma 
"teia associativista" funcionando no Recife, mas, que não necessariamente coadunava com interesses coletivos.

Chamamos, portanto, de "teia associativista recifense" o emaranhado de associações abertas e em pleno funcionamento na cidade do Recife oitocentista. Temos instituições de todos os tipos: (a) aquelas ligadas a "boa sociedade"; (b) aquelas ligadas aos trabalhadores de ofícios buscando melhores condições sociais e de mercado de trabalho e; (c) aquelas ligadas aos professores recifenses preocupadas tanto com melhoria de condições sociais, de mercado de trabalho e da instrução pública e/ou privada. Tais instituiçõeslutaram por diversos motivos, mas, o principal deles era a obtenção de alguns direitos sociais, e faziam isso pelo exercício da cidadania - ou a busca incessante por ela.

Se a partir de Thompson o trabalhador é um eterno fazer-se, ofícios e categorias "classicas" de trabalhadores podem ser ampliados e modificados, ganhando novas configurações e perspectivas. Por isso o debate sobre a categoria "trabalhador" gastaria muito tempo e letras e talvez nós não conseguíssemos expressar em poucas páginas nossas impressões sobre o tema. Numa coletânea de artigos publicados num livro intitulado "Trabalhadores na cidade" os historiadores fizeram um esforço de demonstrar como a palavra "trabalhadores" no plural concentrava sujeitos de ambos os gêneros (trabalhadores e trabalhadoras), das mais diversas funções (comércio, agrícolas, fábricas, cocheiros, carroceiros, canoeiros, prostitutas) e jurisdição (livres e escravizados) numa única palavra. Sem mencionar a relação entre trabalhadores versus vadios, tão cara às autoridades públicas. Eles se organizavam com diversos intuitos (resistir confrontando uma política ou a polícia, negociar uma questão e também para o lazer), mas, eram trabalhadores da cidade. Considerálos nesta localização geográfica (cidade) implica levarmos em consideração uma lógica de espacialidade dinâmica, na qual, esses personagens transitavam entre sua moradia e o trabalho por diversas ruas e ambientes (AZEVEDO et al. 2009). É esse personagem, "o trabalhador", que buscamos neste trabalho. Não todos, mas aqueles que, por ventura, passaram ao longo de sua experiência de vida por uma instrução própria voltada ao exercício de seu ofício.

O estudo sobre diversos ofícios e associações ampliaram suas temáticas com o usoda perspectiva thompsoniana em suas análises: afastaram-se de uma visão economicista clássica e aproximaram-se a uma análise mais sociológica e historiográfica (levando em consideração não apenas o caráter social, mas o processo de devir histórico). Dentre esses ofícios e associações estão as de professores, que assim como os "outros" trabalhadores de ofício, tiveram uma modificação em seu status quo social e profissional, procurando associar-se de 
diversas maneiras em busca de práticas coletivas de cidadania. Suspeitamos que estas práticas coletivas de cidadania estavam baseadas, em primeiro lugar, na experiência individual vivida pelo trabalhador/professor (experiência (1) de acordocom Thompson), embora tivesse inseridas numa lógica de "pertencimento" a um ofício.

\section{Práticas da Sociedade Propagadora da Instrução Pública}

Aos 25 de março de 1878, um grupo de professores primários compôs-se enquanto uma associação denominada Grêmio dos Professores Primários. Esta associação objetivava "promover o aperfeiçoamento da instrução primária na província, fazendo conferências pedagógicas, nas quais eram discutidas entre seus membros as reformas e medidas convenientes à transmissão do ensino e a qualquer assunto concernente à instrução" "3. Entre os sócios efetivos seriam matriculados os professores públicos e particulares da instrução primária para ambos os sexos. Seriam aceitos professores secundários ou funcionários superiores da instrução enquanto sócios honorários. O Monte-Pio foi criado e conservado para amparar os sócios efetivos sem aposentadorias, e em tempos de moléstias, os que ultrapassassem o período de licenças com vencimentos. Também objetivava amparar as famílias em caso de morte do sócio - procedimento normal numa associação de característica beneficente e mutualista ${ }^{4}$.

Em 1906, o estatuto do grêmio adotaria outra finalidade, a de "promover o melhoramento da educação e ensino do povo", comemorativas das grandes datas do Estado de Pernambuco e da União, obviamente falamos de um período marcado já pelo regime Republicano. Os outros fins sociais vinculados à beneficência e ao mutualismo permaneciam intactos.

A Sociedade Propagadora da Instrução Pública foi uma associação formada por políticos e professores influentes na "boa sociedade", inaugurada nos idos de 1872. Com o objetivo de"propagar" a instrução pública, estruturou-se inicialmente um Conselho Superior composto por todos os sócios iniciais da associação, e com Conselhos Paroquiais divididos pela província. Os de Recife eram os Conselhos Paroquiais da Boa-Vista, São José, Santo Antônio, Bairro do Recife (hoje: Recife Antigo), Nossa Senhora das Graças, Poço da Panela, Afogados, Várzea. Também foi responsável pela abertura da Escola Normal (1872) para senhoras (depois nomeada Escola Normal Pinto Júnior), pela Escola de Agricultura no bairro do Monteiro (1878) e da Escola de Farmácia do Recife (1903). 
Analisar a trajetória de alguns dos sócios pode auxiliar na compreensão da ação deles em prol de interesses individuais e coletivos. Dentre os sócios fundadores àqueles reunidos na casa de João Diniz Ribeiro da Cunha, em 3 de agosto de 1872, detalharemos as trajetórias de Felix de Vallois Corrêa, José Soares de Azevedo e João José Pinto Júnior.

Em junho de 1876 faleceu um dos sócios fundadores da SPIP. Porém, por ter sido uma figura pública importante, o Dr. José Soares de Azevedo mereceu as honras de ter uma pequena biografia publicada no Diário de Pernambuco. Nascido na cidade do Porto em 1800, filho único e legítimo do negociante Manoel Soares de Souza Martins e D. Margarida Corrêa da Conceição Martins e Azevedo, estudou na Universidade de Coimbra na Faculdade de Sciencias Naturaes. Foi mandado aos 17 anos para Paris e matriculou-se no curso público de Filosofia e História, sendo também Bacharel em Lettras pela mesma universidade. Publicado um escrito acerca da separação entre Portugal e Brasil, bastante notável à época. Foi deputado no Ceará entre 1852-1856 e apresentou um projeto para a emancipação do ventre escravo, sem grande visibilidade e ridicularizada pelos contemporâneos.

A vida pública não eram as únicas pretensões do Dr. Azevedo, ao passo que abriu na Corte, por pouco tempo, um Colégio regular de Instrução Secundária, posteriormente transferido para Pernambuco, existindo até 1839. Continuou com a trajetória na instrução pública tendo sido nomeado Lente do Lyceu em 1842 e em 1855 foi nomeado professor do Ginásio Provincial. Azevedo também era oficial da Imperial Ordem da Rosa e Sócio Fundador e Presidente do instituto Arqueológico e Geográfico Pernambucano ${ }^{6}$. Ou seja, participou de estancias bem quistas da sociedade imperial e da província em que viveu.

O Dr. João José Pinto Júnior, filho de médico, formou-se em 1855 pela Faculdade de Direito do Recife. Fez parte do grupo conhecido como "geração de 1870"7 . Como político, pertenceu ao partido liberal, mas afastou-se por considerar as eleições cheias de fraude e sem lealdade. Daí dedicou-se a questões educacionais, tendo acumulado nos anos de 1886 e 1890 o exercício de Lente e de Diretor interino da Faculdade de Direito do Recife ${ }^{8}$.

Dentre os sócios mencionados, um professor teve sua trajetória bastante marcada com o envolvimento com a política provincial e associações mutualistas: Felix de Vallois Corrêa. Ele conquistou sua habilitação para lecionar em 1865. Era torneiro e procurava se aperfeiçoar sempre. Após alguns trâmites legais que o impediram de ser titulado ainda em 1862, em 1867 foi empossado para a Vila de Cimbres (interior de Pernambuco). Após um processo longo de pedido de transferências, o professor conseguiu ir para a cadeira da Pedra Tapada (interior de Pernambuco). 
Era sócio da Sociedade dos Artistas Mecânicos e Liberais em 1859, participante de sua rede de compromisso. Em 1867 o professor e sócio lecionava para um grupo de 30 alfabetizandos nos bancos escolares da SAML. Vallois foi o segundo artífice da SAML a se tornar professor público em Pernambuco, demonstrando "a penetração pública do grupo de artífices e a eficiência de suas redes de compromisso" (MAC CORD, 2012, p. 238). Em 1870 o artífice acumulava status, conforme os elogios do Delegado Literário de Limoeiro por não empregar castigos corporais em seus alunos, e por ter muito zelo e dedicação enquanto professor público de primeiras letras. Tal destaque garantiu uma transferência para a $4^{\mathrm{a}}$ Cadeira da Freguesia da Boa Vista (bairro central do Recife) e, com isso,ocupou o cargo de diretor do Liceu em 1871 e manteve 1874.

O exame do organograma da Diretoria das Aulas do Liceu de Artes e Ofícios demonstrou que, apesar de o projeto da escola profissionalizante estar vinculado aos que ocupavam o topo da pirâmide social, foram os mestres de ofício pernambucanos que efetivamente controlaram aquela instância de poder. Mais do que simplesmente comandar, Felix de Valois Correia exercia com sucesso a gestão pedagógica do estabelecimento de ensino Para tanto, o perito das chamadas "artes úteis" e professor público contou com o precioso auxílio de alguns colaboradores (MAC CORD, 2012, p.299).

Esse torneiro formado no Consistório Leste da Igreja de São José do Ribamar, logradouro mais antigo da SAML, tornou-se professor público, conquistou status no interior da sociedade recifense, utilizando-se muito bem das redes de clientela motivadas e mantidas pela associação de artífices. Cerca de dez anos após entrar na instrução pública, já foi considerado apto a ocupar cargos importantes na SPIPpor outros professores e por colegas artífices(lembrando que foi um dos professores participantes da primeira reunião da SPIP).

Pretendemos explicitar o modo como os sócios da SPIP, antes mesmo de instaurar a associação, construíram e mantiveram redes clientelares, aparentemente com o objetivo de propagar a instrução pública e a formação de trabalhadores regionais para o exercício de cargos na própria cidade do Recife. Se os benéficos do mutualismo, da beneficência e do socorro mútuo eram encarnados pela sociedade civil e pela sociedade política do século XIX recifense, não podemos escapar à tentativa de interpretá-los numa perspectiva de que "associar-se" traziam vantagens sociais profícuas aos indivíduos; mantinham um jogo político interno amplamente relacionado às redes políticas traçadas no exterior da associação; era um meio de empregar os ideais desses sujeitos na sociedade recifense, permitido até pela 
verticalidade e horizontalidade das relações entre as associações e entre as associações e a esfera política recifense.

\section{Os salários dos professores públicos de primeiras letrasno Recife e Olinda (1860-1880)}

Ao longo da segunda metade do século XIX, o magistério público foi cada vez mais se hierarquizando em função dos valores dos ordenados recebidos e/ou conquistados pelos professores públicos primários, ora com relação às variações salariais entre os professores da capital e do interior, ora em função das discrepâncias existentes entre os ordenados pagos a determinados funcionários públicos e àqueles pagos aos próprios professores primários da capital.

A partir do esforço de traçarmos as trajetórias de alguns nomes importantes do magistério público recifense, encontrados nos códices da série Instrução Pública, ao longo do século XIX. Levando em consideração as variações salariais, variações de aluguéis recebidos para as casas de aula e dos expedientes mensais - expressão à época utilizada para especificar a soma dos principais expedientes práticos recebidos pelos professores ao mês -, somos tentados a afirmar que tanto os poderes públicos quanto os professores reconheciam as vantagens individuais conquistadas ao longo do exercício da docência, bem como as estratégias diferenciadas de conseguir as benesses governamentais, indicativos de um grupo, marcado por privilégios pessoais, desde a constituição como categoria profissional. Este argumento baseia-sena comparação tanto das informações contidas na tese de Adriana Silva (2006) relativas aos salários dos docentes de primeiras letras no Recife na primeira metade do século XIX, quanto aos dados fornecidos por uma tabela encontrada nos códices da Instrução Pública correspondente aos anos de 1860 a $1866^{9}$. Vejamos.

Desde 1843, em Santo Antônio (bairro central do Recife), continuava a ensinar o padre Vicente Ferreira de Siqueira Varejão. Este professor apareceu nas fontes correspondentes aos anos de 1860 a 1866 com um ordenado de 340 mil réis, 200 mil réis de gratificação por exercício na docência, 166.660 mil réis de gratificação por 12 anos de serviço, 520 mil réis por 25 anos de serviço e 276 mil réis para aluguel da casa de aula.

Faremos um breve esforço de comparação. Se fosse no ano de 1876, considerando o bairro de Santo Antônio, oprofessor angariava a renda mínima dos votantes daquela localidade,enquadrando-se num grupo de $26 \%$ dos cidadãos à época com renda entre 400 e 
800 mil réis. O professor estaria incluído no grupo de 24 docentes votantes do mesmo bairro, caracterizado por intenso comércio de luxo e pela elite burocrática. ${ }^{10}$

Outro professor bastante conhecido foi Simplício da Cruz Ribeiro, o qual desde 1856 exercia a docência na povoação do Pires e em 1857 encontrava-se na Boa Vista (bairro central do Recife). Em 1866, o mesmo professor reapareceu nas fontes provendo a primeira cadeira da Boa Vista, recebendo 840 mil réis de ordenado, 200 mil réis de gratificação e 260 mil réis de aluguel anual da casa de aula. Considerando uma expectativa feita por Adriana Silva (2006), na qual os professores primários dos bairros de Santo Antônio e da Boa Vista do Recife, nos anos 50 do século XIX, recebiam em torno de 500 mil réis de ordenado e 200 mil réis de gratificação, podemos afirmar que em torno de 10 anos de magistério, o professor Simplício aumentou o seu ordenado em 340 mil réis.

O professor Simplício, considerando o ano de 1876, pertencia ao grupo dos 31,6\% dos votantes do bairro da Boa Vista (localidade dominada por homens de alta renda)que ganhavam entre 800 mil réis e 2 contos de réis mensais ${ }^{11}$.

Desde 1843, o professor Luiz Cyriaco da Silva trabalhava no magistério em Abreu do Una (interior de Pernambuco), época na qual recebia um ordenado anual de 400 mil réis. Em 1866, reapareceu trabalhando em Afogados (arrabalde do Recife), recebendo um ordenado anual de 720 mil réis, 200 mil réis de gratificação por exercício e 260 mil réis de aluguel anual da casa de aula.

Com relação à situação do professor Luiz Cyriaco do bairro de Afogados, majoritariamente povoado por agricultores e artistas em 1876, poderíamos enquadrá-lo num grupo de $11 \%$ dos votantes da localidade com renda entre 400 mil réis e menos de 800 mil réis ${ }^{12}$.

Na primeira cadeira de São José (bairro central do Recife), ensinava a professora Joanna Justina de Siqueira Varejão, parente do professor Vicente Varejão, do bairro de Santo Antônio. Esta professora lecionava inicialmente em Igarassu desde 1852, ganhando 400 mil réis de ordenado e 50 mil réis de aluguel da casa de aula. Em 1866, angariou 720 mil réis de ordenado, 200 mil réis de gratificação, 184 mil réis de gratificação por 15 anos de serviço e 276 mil réis de aluguel da casa de aula.

Se fosse em 1876, a professor Joanna Justina, com sua trajetória salarial, enquadravase nos $41,3 \%$ dos votantes de São José (bairro dominado por artistas e trabalhadores manuais) com renda entre 400 mil réis e menos de 800 mil réis ${ }^{13}$. 
Não encontramos registros nos códices da série Instrução Pública de reclamações por parte dos professores públicos quanto aos baixos salários concedidos pelas autoridades entre os anos de 1860 e 1870. Entretanto, havia discussões de igualdade salarial entre professores e professoras, como o caso da professora de São Pedro Mártir (um dos locais centrais de Olinda) D. Rosa Maria Fonseca de Albuquerque que, em 1860, solicitou a passagem do seu ordenado de $500 \$ 000$ réis para $600 \$ 000$ réis (desde o art. 4 da lei n. 429 de 1857), valor recebido pelos professores ${ }^{14}$. A professora teve seu pedido aceito.

Nas caixas de Petições enviadas a Assembleia Legislativa, a discussão sobre aumento salarial parece ter sido acalorada. Em 12 de março de 1866, um abaixo-assinado feitos por vários docentes ${ }^{15}$ foi enviado aos deputados provinciais solicitando $\mathrm{o}$ aumento dos vencimentos dos professores da capital de 1:040\$000 para 1:500\$000. Alegando insuficiência nos atuais vencimentos para se viver com "honestidade" em uma capital como Recife, os professores requerentes se compararam aos empregados das repartições públicas, os quais, com exceção dos contínuos, ganhavam mais do que eles. Vejamos a riqueza argumentativa com a qual se baseia os professores para justificar a sua petição:

\begin{abstract}
"[..] entretanto, sendo as localidades as mesmas, as precisões necessariamente as mesmas, para uns e para outros, principalmente atendendo-se a que categoria desses empregados, a quem os suplentes [professores] se referem, não é superior aos dos professores. Um $1^{\circ}$ escriturário da Tesouraria Provincial, por exemplo, tem 1:400\$000 réis, além da gratificação de $300 \$ 000$ réis das loterias; e ainda maiores vencimentos têm os da Secretaria da Presidência, Policiais do Consulado, sendo demais alimentados para a esperança de promoção. Além disso, os professores de instrução primária do Ginásio Provincial e da Escola Prática anexa a normal percebem, o primeiro 1:700\$000 réis e o segundo 1:500\$000 réis. O que pode justificar essa desigualdade quando nem o trabalho, nem a habilitação desses professores são superiores aos dos suplentes? Os pedidos dos suplentes é tão justo e razoável que em 1855 já foi reconhecido pelo Exmo. Sem. Presidente da Província,"16.
\end{abstract}

A petição acima indicou uma tentativa de união dos professores de primeiras letras em prol de uma reivindicação à categoria profissional. Não podemos nos precipitar em afirmar que tal união pode ter resultado em um "movimento" posterior de igualdade salarial a todos os professores (do interior e da capital), pois não era de seus interesses. Muito embora, esta união tenha se estabelecido em prol de melhores condições para a docência, os salários dos professores da capital tendiam a aumentar cada vez mais nas décadas finais do Império, em Pernambuco. A diferença dos ordenados encontrados nas trajetórias dos professores e no aumento solicitado nos Anais da Assembleia são indícios de como a hierarquização salarial 
por localização de ensino inseriu os docentes individualmente na "teia da cidadania" do Império.

Vale lembrar que, anteriormente a promulgação da Lei Saraiva de 1881, a constituição de 1824 relegou os direitos políticos estabelecendo as condições para os votantes e os nãovotantes. Podiam votar todos os homens de 25 anos com renda mínima de 100 mil-réis. Todos os cidadãos qualificados eram obrigados a votar, com exceção das mulheres e dos escravos, não considerados cidadãos. Os dados também não excluíam a população pobre de votar, tampouco a população analfabeta. A limitação de renda era pouco importante, pois a maioria da população ganhava 100 mil-réis. Em comparação aos padrões de alguns países europeus, antes de 1881 no Brasil votavam cerca de $50 \%$ da população masculina adulta, se observado que em torno de 1870 apenas votavam 7\% da população na Inglaterra (CARVALHO, 2008).

Afirmamos que a cidadania docente, quando se tratava de renda, era conquistada por práticas individuais. O que chama atenção é que os(as) professores(as) públicos(as), da capital, faziam parte da seleta porcentagem de votantes com renda entre 400 mil réis e 800 mil reís; e, em casos específicos, inseriam-se no grupo dos votantes de alta renda, entre 800 mil réis e 2 contos de réis, chegando a lecionarem e permanecerem em bairros dominados por uma alta burocracia, como no caso do bairro de Santo Antônio.

\section{As gratificações dos professores públicos de primeiras letrasno Recife e Olinda (1860-} 1880)

Acrescentadas aos ordenados dos professores, a depender de uma série de prerrogativas, estavam as gratificações. Nas décadas de 1870-1880, percebemos o aumento do número de solicitações de gratificações, bem como a diversidade das mesmas. A primeira denominada "gratificação por tempo de serviço" consistia numa das principais solicitações enviadas pelos professores públicos às instâncias governamentais e dependiam da forma como era exercida a docência ao longo dos anos (conhecida como "gratificação de mérito"). De acordo com as fontes, entre os anos de 1870-1880, a permanência na docência pública digna de gratificação variava entre 12 anos (até a lei n. 369, de 14 de maio de 1855), 15 anos (desde a lei n. 369, de 14 de maio de 1855 e a lei n. 598, de 13 de maio de 1864), 25 anos (desde a lei n. 1143, 08 de julho de 1874) e 35 anos (desde o regulamento de 04 de abril de 1879). Para obtê-las os docentes dependiam não apenas da legislação vigente na época, mas dos seus méritos, conquistados ao longo do período de trabalho e da frequência com que recorriam às autoridades da instrução pública. 
Em 1864, o diretor Silvino Cavalcanti Albuquerque aparentou estar bem preocupado com a forma como a gratificação por tempo de serviço deveria ser concedida aos professores. Esta não deveria exceder a quinta parte dos vencimentos, marcadas pela lei n. 369, de 14 de maio de 1855, aos professores que se distinguissem no ensino por mais de quinze anos. "A expressão - mais de quinze anos - deixa ver que a gratificação pode ser concedida ao professor que tiver 15, 16 e mais anos de serviços". ${ }^{17}$ Então, na década de 1860, os professores do $1^{\circ}$ grau que ganhavam 600 mil réis anuais, podiam obter 200 mil réis de gratificação.

Por outro lado, a recorrência de tais solicitações causavam entraves quanto a sua aprovação, a forma de concessão e a legislação vigente. Casos não faltam para exemplificar esses três aspectos.

Cruzando as fontes e seguindo os rastros da discussão supradita, existiram professores que recorreram a instâncias diferentes, outros foram recordistas na tentativa de convencer a Inspetoria da Instrução Pública.

Izidoro de Freitas Gamboa, nomeado desde 28 de fevereiro de 1857, recorreu às autoridades públicas em 1876 com o pedido de gratificação por 15 anos de serviço. Exercendo a docência, em princípio, na Muribeca (subúrbio do Recife), onde regeu gratuitamente uma aula noturna desde agosto de 1872 ao fim de 1873 , removeu-se para a cadeira de São José (bairro central do Recife) em fevereiro de 1874. Graças à "espontaneidade" e "zelo" como professor gratuito nas escolas noturnas, e tendo identificado o diretor interino João Barbalho Uchôa Cavalcanti que o governo não podia estabelecer as escolas noturnas de adultos por toda a parte da província, a gratificação do professor não causava nenhum problema ao diretor geral $^{18}$. Mas, foi o que não se observou nos anos posteriores.

Em 1877 o mesmo professor recorreu à inspetoria da instrução duas vezes. Nestas ocasiões, o mesmo diretor João Barbalho Uchôa Cavalcanti, remontou a petição do ano de 1876 para justificar a sua posição frente ao caso. Segundo o diretor, o art. 15 da lei de 1143 revogava o pedido do professor, visto que tinha 15 anos de docência ${ }^{19}$. A dita lei reiterava os parágrafos 26, 27 e 28 da lei n. 598, de 13 de maio de 1864. Suscintamente, três critérios foram destacados nos três parágrafos para concessão de gratificações:

1. O pedido de gratificação não devia exceder a quinta parte dos vencimentos recebidos;

2. O "zelo" e assiduidade no ensino, bem como o aproveitamento dos alunos nos exames; 
3. Os professores providos antes da supracitada lei receberão a gratificação ao completarem 12 anos de serviço. Porém sem exceder a quarta parte do ordenado ${ }^{20}$.

Os três critérios de concessão da gratificação por tempo de serviço estavam diretamente atrelados à forma como o ensino era conduzido pelo professor, sem exceder uma parte do ordenado ou vencimento. Imaginemos, pois, quantos professores se esforçavam (ou não) em qualificar a maioria dos alunos nos exames anuais.

Conhecedor dos tramites legais, Izidoro de Freitas Gambôa recorreu mais duas vezes em 1880. Nesta situação, o professor alegou estar dentro dos critérios estabelecidos pela lei n. 1513, de 29 de julho de 1880, cuja concessão deu-se pelo mérito com o qual aprovou seus alunos nos exames anuais ${ }^{21}$. Não temos informações de quantos alunos foram aprovados, tampouco quais alunos. Em 1881, o dito professor reclamou contra a cláusula de lhe ser abonada a concessão da gratificação de mérito e antiguidade de que tratam os artigos 144 e 148 do regulamento vigente, isto é, o pagamento da metade dos vencimentos como gratificação aos professores com 25 anos de efetivo exercício. ${ }^{22}$ Porém, apenas em 1881, as solicitações anteriores foram comprovadas com documentos necessários, a respeito dos 25 anos completados no magistério.

Izidoro, a esta altura, já estava em condições de aposentar-se (ou jubilar-se, de acordo com o termo empregado nos documentos). Assim, em 1888, em fins do Império, o dito professor requereu a computação de sua aposentadoria à gratificação de mérito, não aceita por não comprovar a petição com documentos necessários ${ }^{23}$.Fato que justifica o seu retornou às instâncias da instrução para comprovar sua aposentadoria à gratificação de mérito já no ano de 1889, finalmente aprovada pelo então diretor João Barbalho Uchôa Cavalcanti ${ }^{24}$.

O caso de Izidoro é um exemplo, dentre tantos outros encontrados, de que alguns professores, embora sendo da capital da província pernambucana, precisavam conquistar as gratificações incididas sobre a docência. Outro aspecto interessante nas recorrências é de que durante todos os anos demonstrados, o diretor da instrução foi o mesmo, João Barbalho Uchôa Cavalcanti.

\section{Práticas de “desconforto” dos docentes públicos de Recife e Olinda (1860-1880)}

Para além dos expedientes salariais e de gratificação que cercavam o trabalho docente, outras formas de benesses governamentais durante a segunda metade do XIX, conquistadas por privilégios ao longo da careira possuíam os seus desdobramentos nas vidas dos seus profissionais, na organização da instrução pública e na imagem do(a) docente nos potentados 
locais. Tratava-se de um fenômeno atribuído como "desconforto" dos docentes públicos que atuaram no eixo Recife-Olinda, entre os anos de 1860 e 1880, analisado, com profundidade, na dissertação intitulada "Sinais do "desconforto" no exercício da docência pública no Recife e Olinda (1860-1880)" (LIMA, 2014).

A partir da leitura e sistematização de 20 códices de série Instrução Pública, entre os anos de 1860 a 1880, obtivemos 2884 registros, sendo 1614 registros referentes, especificamente, aos professores públicos entre Recife e Olinda: aproximadamente 1233 professores públicos e 381 professores particulares. A respeito dos professores públicos, identificamos os assuntos mais frequentes nos códices da Instrução Pública:

\section{Gráfico 1}

Principais assuntos referentes aos professores públicos, nos códices da série Instrução Pública (1860-1880)



A partir do gráfico, destacamos que os pedidos de licenças, de transferências, permutas e substituições, por parte dos professores públicos, excedem todos os outros. E destacamos também que os pedidos de licenças médicas são recordistas entre as solicitações dos professores públicos.

Diante dos dados, a base de nossa argumentação foi a de que houve, de acordo com os registros encontrados, no mínimo, um significativo "desconforto" no exercício da docência 
em ambas as cidades, em um período anterior ao recente processo histórico de precarização do trabalho docente. Ou seja, eram majoritárias as problemáticas práticas descritas pelos poderes públicos em relação às necessidades de afastamento do docente no exercício de seu trabalho.

Com base nesse "achado", defendemos que as experiências dos professores públicos em se afastarem foram motivos importantes para a criação de um corpus legislativo que, cada vez mais, pretendeu regrar as suas práticas. Porém, a normatização nem sempre impediu o costume, ou seja, o uso do "discurso" de um fenômeno coletivo, como forma de angariar as benesses governamentais. E assim, entre a regra e o costume, a docência se constituiu como categoria profissional (LIMA, 2014). Vejamos alguns casos específicos de professores(as) públicos(as) que recorreram às instancias da instrução pública com o intuito de angariarem a aprovação de diferentes petições de afastamento do local de trabalho, ao longo dos anos de magistério.Destacaremos o caso do professor padre Maximiniano Sobreira.

A partir da leitura dos dados encontrados nos códices da Instrução Pública, o tempo solicitado na maioria dos pedidos de abono das faltas por doença ultrapassou o prazo de oito dias estabelecido pelo Regulamento de 1874, e, mesmo assim, a maioria dos professores não comprovava a doença com atestado médico para solicitar tal abono ${ }^{25}$.

Em casos de faltas por motivo de transferência, durante a década de 1860, a concessão do abono seguiria as atestações dos delegados literários ou demais autoridades próximas à escola do professor. No decorrer da década de 1870 ficou estabelecido, a partir do art. 151, n. III do Regulamento de 1874, que as faltas seriam abonadas em casos de transferências por acesso, isto é, via ascensão das entrâncias onde se localizavam as escolas públicas das seguintes maneiras:

1. Se vagasse ou fosse criada alguma cadeira de $2^{\mathrm{a}}$ entrância, o professor de $1^{\mathrm{a}}$ entrância, com maior tempo de serviço no magistério, teria acesso a esta;

2. Se vagasse ou fosse criada alguma cadeira de $3^{\mathrm{a}}$ entrância, o professor de $2^{\mathrm{a}}$ entrância poderia, sem que deixasse o exercício de sua cadeira, se candidatar a ela ao enviar o requerimento à repartição da instrução pública.

A vacância ou criação das cadeiras de $3^{\mathrm{a}}$ entrância eram anunciadas na imprensa pelo inspetor geral. Em casos de não haver concurso público para a concorrência a cadeira de $3^{\mathrm{a}}$ entrância, o conselho literário se encarregaria de elaborar e enviar a presidência da província uma lista com os dez professores de $2^{\text {a }}$ entrância mais competentes e com maior tempo de serviço. O presidente da província escolheria um dos professores para ocupar a cadeira ${ }^{26}$. 
As entrâncias emergiram na documentação, pela primeira vez, por meio do texto da lei n. 1124, de 17 de junho de 1873. Segundo esta lei, as escolas públicas primárias seriam divididas em $1^{\mathrm{a}}, 2^{\mathrm{a}}$ e $3^{\mathrm{a}}$ entrâncias, levando em consideração a distância da capital, a divisão civil e judiciária da localidade na qual pertencia a escola, a quantidade da população e o desenvolvimento econômico local ${ }^{27}$.

Cinco anos mais tarde, a "Seção II - Das Faltas" do Regulamento Orgânico da Administração do Ensino Público de 1879 reafirmou os dispositivos para os pedidos de abono das faltas por motivos de doenças e transferências encontrados no Regulamento de $1874^{28}$.

O caso de Maximiniano Narcizo Sobreira de Mello foi emblemático dentre os outros registros de afastamento investigados na década de 1860. Durante seu percurso na docência pública, este professor teve uma relação pouco amigável com as autoridades. Em seu primeiro registro, datado de 1860, o diretor da instrução pública deixou a cargo do presidente da província, Luiz Barbalho Muniz Fiuza, a aprovação do abono das suas faltas, tendo em vista os inúmeros afastamentos já solicitados anteriormente pelo professor ${ }^{29}$. Neste ano, nenhum parecer do presidente foi verificado.

No ano seguinte, um novo diretor geral da Instrução Pública, Joaquim Pires Machado Portella, motivado por ter que responder a um pedido de quarenta dias de licenciamento médico feito pelo professor, descreveu a trajetória profissional de Maximiniano.

Aquele professor, segundo o Diretor Geral, havia sido nomeado para assumir a cadeira pública de Ipojuca, em 26 de novembro de 1857. Menos de um ano depois, permutou-se para o Curato da Sé, em Olinda. Pouco mais de dois anos depois, em 21 de março de 1861, transferiu-se para o Poço da Panela. De acordo com a autoridade pública, contabilizando o tempo de permanência efetiva do professor nas ditas cadeiras, o diretor afirmou ter sido apenas de 11 meses e 03 dias na primeira cadeira; 02 anos e 22 dias na segunda cadeira; e no exercício da terceira cadeira, contava, então, 10 meses. Assim, "no período de 03 anos e 25 dias, tem ele [o professor] dado muitas faltas e motivou diversas representações que a presidência da província (V) dirigiu a esta Diretoria"30.

Insatisfeito, Maximiniano recorreu à diretoria alegando estar doente e impedido de dar aulas. O Inspetor da Instrução Pública, Dr. João Silveira e Souza, negou novamente o pedido argumentando que, além de faltarem provas documentais, o professor ${ }^{31}$ não havia se dirigido ao Delegado Literário, conforme era exigido pelo parágrafo 3 do art. 66, da lei n. 369, de 14 de maio de 1855, que regulamentava aquela situação. 
Em 1863, Maximiano requereu à Diretoria da Instrução, uma nova licença médica. Este pedido aconteceu depois do professor não justificar o abandono de sua cadeira durante sete meses para ir a Recife. Desta vez, munido da defesa do Procurador Fiscal- figura decisiva no controle dos pagamentos dos funcionários públicos- corroborava seu direito de receber os ordenados pelo tempo de afastamento.

Mesmo munido da defesa do Procurador Fiscal, seu pedido foi negado pela Diretoria da Instrução Pública, em virtude das ausências injustificadas. O professor também alegou, segundo a fala das autoridades, a justiça em receber abono das faltas com os ordenados correspondentes aos meses de afastamento por meio do atestado médico do Dr. Sarmento, mas a veracidade do documento também não convenceu a Diretoria ${ }^{32}$.

Como visto, o professor Maximiniano intentava receber salário sem trabalhar e obteve o apoio do Procurador Fiscal para conseguir a aprovação de sua petição. Embora não possa ser representativo de toda a docência pública, o caso em questão exemplifica como, dentre os docentes, também havia práticas clientelistas, imunes aos aparatos legais.

Porém, nos termos da lei, a não justificativa das faltas dos professores públicos culminaria no desconto proporcional dos seus salários. Os Delegados Literários não podiam abonar mais de três faltas seguidas e, apenas com motivo "justo" e "urgente", concederiam a licença. Finalmente, em 1864, Maximiniano reapareceu na documentação solicitando sua reintegração ao magistério, em qualquer uma das cadeiras localizadas em Ipojuca, Curato da Sé ou Afogados. Em vista do fato de nenhuma das três cadeiras solicitadas estarem vagas, o requerimento foi negado ${ }^{33}$. Por fim, num livro intitulado "folhinha católica", Maximiniano, cansado das tentativas em vão, já como professor do Poço da Panela, pediu demissão da docência pública ${ }^{34}$.

Em virtude da ausência do atestado médico não podemos afirmar se a doença que acometeu o professor decorreu do exercício da profissão ou não. Da mesma forma, não podemos justificar os motivos pelos quais o dito professor abandonou sua aula para ir à capital. O fato é que Maximiniano teve, ao todo, sete anos de docência pública, de 1857 (ano de provimento da aula pública) até 1864 (ano do pedido de demissão da docência). Nestes poucos anos sofreu um intenso desconforto, aonde quer que tenha ido.

Pensemos em como as experiências dos professores públicos em se afastarem foram motivos importantes para a criação de um corpus legislativo que, cada vez mais, pretendeu regrar as suas práticas. Porém, a normatização nem sempre impediu o costume, ou seja, o uso 
do "discurso" como forma de angariar as benesses governamentais. E assim, entre a regra e o costume, a docência se constituiu como categoria profissional.

\section{Considerações finais}

Ao longo deste artigo, analisamos as práticas dos professores públicos primários em dois aspectos centrais: as associações de docentes, em específico, a Sociedade Propagadora da Instrução Pública de 1872; e os principais expedientes práticos do trabalho docentes, tais como salário, gratificações, licenças médicas, transferências, permutas, faltas ao ensino, solicitações de matérias didáticos, métodos de ensino etc.

Com relação ao associativismo docente, destacamos o fato de muitas das práticas associativistas não demonstrarem efetivamente uma ação coletiva, objetivando uma consciência por parte dos trabalhadores departiciparem de uma classe/ofício/profissão comum. E pelo fato da própria categoria "trabalhador" ser difusa e de difícil objetivação, os professores ao passarem pelo processo deprofissionalização também participaram dessa característica (associativista) ao pugnarempor "direitos coletivos".

Lidando com professores da capital da província, percebemos que os mesmos possuíam salários valorizados se comparados as situações dos professores do interior, sendo suficientes para ingressarem, em alguns casos, no "rol" da burocracia recifense, bem como recebiam um salário equiparado aos demais funcionários provinciais, os quais tenderam a aumentar nos anos finais do século XIX, somados às gratificações.

Por intermédio de um quantitativo majoritário de afastamento dos professores dos locais de trabalho, tendemos a afirmar que o discurso do "desconforto" docente atrelava-se às necessidades individuais dos(as) professores(as) públicas(as), especialmente por serem conhecedores das legislações que regravam o afastamento dos locais de trabalho.

Afirmamos que, no século XIX, a docência como categoria profissional foi marcada por práticas individuais de cidadania, isto é, embora houvesse a existência de grupos docentes, estes desenvolviam estratégias pessoais, de acordo com privilégios conquistados ao longo da carreira, as quais, na prática, afastavam-se de constituírem uma identidade docente. 


\section{Notas}

${ }^{1}$ ESTATUTOS da Associação dos Empregados no Comércio de Pernambuco. Pernambuco: Tipografia do Jornal do Recife, 1892. P. 3. Folhetos Raros II, APEJE.

${ }^{2}$ ESTATUTOS da União Beneficente dos Caixeiros de Hotéis de Pernambuco. Pernambuco. Recife: Typografia Moderna, 1911. (APEJE: Códice, Folhetos Raros II).

${ }^{3}$ Almanak Administrativo, Mercantil, Industrial e Agrícola de Pernambuco. Recife: Typographia Mercantil, 1883. p. 383.

4 ESTATUTOS do Grêmio dos Professores Primários em Pernambuco. Recife: Typographia do Tempo, 1878.

${ }^{5}$ ESTATUTOS do Grêmio dos Professores Primários em Pernambuco. Recife: Typographia do Tempo, 1906.

${ }^{6}$ Quinta-Feira 8 de Junho de 1876. Diário de Pernambuco 1 Jan. a 31 Mar. 1876. Rolo No 111 (Setor de Microfilmes - FUNDAJ)

7“A geração de 1870" enquanto movimento intelectual buscou no repertório político-intelectual de fins dos oitocentos os recursos que lhe permitisse exprimir sua crítica ao regime imperial numa forma distinta da tradição liberal-romântica inventada pela elite imperial. A carreira docente, além das relações associativista, era bastante preterida por esse grupo de intelectuais recifenses, meio pelo qual advinha de um sistema de apadrinhamento sobre os critérios de preenchimento de tal cargo público e a possibilidade de se montar uma rede de clientela com maiores extensões. Cf. (ALONSO, 2002; CARVALHO, 2012).

${ }^{8}$ MEMÓRIA da Sociedade Propagadora da Instrução Pública em Pernambuco. Pernambuco, 1892. (Folhetos Raros II - APEJE).

${ }^{9}$ Os comparativos das faixas salariais dos professores supracitados basearam-se, com relação a primeira metade do século XIX, na tese de Adriana Silva. A este respeito ver SILVA, Adriana Maria Paulo da. Processos de construção das práticas de escolarização em Pernambuco, em fins do século XVIII e primeira metade do século XIX. Recife: Editora Universitária da UFPE, 2007. Com relação aos anos de 1860 a 1866, os comparativos baseiam-se nos dados escritos pelo secretário da instrução pública, João Diniz Ribeiro da Cunha, em 30 de junho de 1866. APEJE: Série Instrução Pública - IP 19 (1866), 02 folhas em anexo.

${ }^{10}$ Para o bairro de Santo Antônio encontra-se os seguintes dados relativos à renda, em mil réis, dos votantes: 200 e menos de 400, 85 votantes (7,3\%); entre 400 e menos de 800, 297 votantes (26\%); entre 800 e menos de 2:000, 478 votantes $(41,5 \%)$; mais de $2: 000,291$ votantes $(25,2 \%)$; total de 1151 votantes $(100 \%)$. Ver. SOUZA, Felipe Azevedo e.Direitos políticos em depuração: A Lei Saraiva e o eleitorado do Recife entre as décadas de 1870 e 1880.2012. 234f.Dissertação (Mestrado em História) - Programa de Pós-Graduação da Universidade Federal de Pernambuco (UFPE), Recife, 2012, p. 100

${ }^{11}$ Para o bairro da Boa Vista encontra-se os seguintes dados relativos à renda, em mil réis, dos votantes: entre 200 e menos de 400, 127 votantes (10,4\%); entre 400 e menos de 800, 430 votantes $(35,2 \%)$; entre 800 e menos de 2:000, 386 votantes $(31,6 \%)$, mais de $2: 000,277$ votantes $(22,8 \%)$; Totalde 1220 votantes $(100 \%)$. Ver. SOUZA, Felipe Azevedo e.Direitos políticos em depuração: A Lei Saraiva e o eleitorado do Recife entre as décadas de 1870 e 1880.2012. 234f.Dissertação (Mestrado em História) - Programa de Pós-Graduação da Universidade Federal de Pernambuco (UFPE), Recife, 2012, p. 120.

${ }^{12}$ Para o bairro de Afogados encontra-se os seguintes dados relativos à renda, em mil réis, dos votantes: entre 200 e menos de 400,1315 votantes (77\%); entre 400 e menos de 800,190 votantes $(11,1 \%)$; entre 800 e menos de 2:000, 128 votantes $(7,5 \%)$ Mais de 2:000,75 votantes $(4,4 \%)$; Total de 1708 votantes $(100 \%)$.

${ }_{13}$ Para o bairro de São José encontram-se os seguintes dados relativos à renda, em mil réis, dos votantes: entre 200 e menos de 400, 419 votantes (27,8\%); entre 400 e menos de 800, 628 votantes $(41,3 \%)$; entre 800 e menos de 2:000, 382 votantes $(25,1 \%)$; mais de 2:000, 89 votantes $(5,8 \%)$; Total de 1518 votantes $(100 \%)$. Ver. SOUZA, Felipe Azevedo e.Direitos políticos em depuração: A Lei Saraiva e o eleitorado do Recife entre as décadas de 1870 e 1880.2012. 234f.Dissertação (Mestrado em História) - Programa de Pós-Graduação da Universidade Federal de Pernambuco (UFPE), Recife, 2012, p. 110.

${ }^{14}$ APEJE: Série Instrução Pública - IP 12 (1860), p. 72.

${ }^{15}$ No final do documento aparecem as assinaturas dos docentes em questão, a saber: João José Rodrigues, Serafim Pereira da Silva Monteiro, Simplicio da Cruz Ribeiro, Francisca das Chagas Ribeiro de Oliveira, Geminiano Joaquim de Miranda, Berlamino Guedes Alcoforado, Maria Salomé de Siqueira Varejão, Benjamin Constant da Cunha Sales, Joana Justina de Siqueira Varejão, Digna de Santa Rosa, Maria da Assumpção de Andrade Luna, Porfiria Jesuina Baptista de Oliveira, Tereza Josephina da Cunha Sales, Sophia Guilhermina de Mello, Rodrigo Lobo de Miranda, Alexandrina de Lima e Albuquerque, Antonio Rufino de Andrade Luna, Emilia Candida de Melo Luna. Vale ressaltar que alguns nomes estão ilegíveis, estando aqui apenas os possíveis de serem lidos. ALEPE - Série Petições. Caixa 132P (1866-1868), sem numeração de página.

${ }^{16}$ ALEPE: Série Petições. Caixa 132P (1866-1868), sem numeração de página.

${ }^{17}$ APEJE: Série Instrução Pública - IP 16 (1864), p. 351 (F e V).

${ }^{18}$ APEJE: Série Instrução Pública - IP 31 (1876), p. 426 (F e V). 
${ }^{19}$ APEJE: Série Instrução Pública - IP 32 (1877), p. 67 e 345.

${ }^{20}$ PERNAMBUCO. Lei $n$. 598, de 13 de maio de 1864. Cria a Escola Normal na cidade do Recife. In: PERNAMBUCO. Coleção de Leis Provinciais de. Estante 29. Pratileira 02. Brasileira 02. n. 22. Ano 61/69. Ano de 1864, p. 107-108, APEJE, Recife-PE.

${ }^{21}$ APEJE: Série Instrução Pública - IP 36 (1880), p. 160 e 308.

${ }^{22}$ Cf: APEJE: Série Instrução Pública - IP 37 (1881), p. 192. REGULAMENTOORGÂNICO DA ADMINISTRAÇÃO DO ENSINO PÚBLICO. Ano de 1879, p. 28, APEJE, Recife-PE, respectivamente.

${ }^{23}$ APEJE: Série Instrução Pública - IP 48 (1888), p. 275-276.

${ }^{24}$ APEJE: Série Instrução Pública - IP 50 (1889), p. 196-197.

${ }^{25}$ LAPEH: Art. 151, N. I, da "Seção II - Das faltas”. In: Diário de Pernambuco (Recife), 21/12/1874, p. 01.

${ }^{26}$ PERNAMBUCO. Regulamento da Instrução Pública de 1874. Apresenta o Art. 151, N. III, da "Seção II - Das faltas". In: Diário de Pernambuco (Recife), 21/12/1874, p. 01. Nos casos das transferências via ascensão de entrâncias, denominada na fonte por "Remoção por Acesso", decorre da lei n. 1124, de 17 de junho de 1873. As escolas de $1^{\mathrm{a}}$ entrância ficavam nas localidades mais afastadas da capital, as escolas de $2^{\mathrm{a}}$ entrância localizavamse nos arrabaldes da capital e as de $3^{\mathrm{a}}$ entrância nas freguesias centrais da capital. Ver. PERNAMBUCO. Regulamento da Instrução Pública de 1874. Apresenta os Arts. 156 a 159, "Seção I - Da remoção por acesso". In: Diário de Pernambuco (Recife), 21/12/1874, p. 01.

${ }^{27}$ Cf. PERNAMBUCO. Art. 13. Lei n. 1124, de 17 de junho de 1873. Autoriza o presidente da província a expedir os regulamentos necessários para a reorganização do ensino primário e secundário. In: PERNAMBUCO. Legislação Provincial de. Estante 29. Prateleira 02. Número 29. Ano (1865-1877). Ano de 1873, p. 70, APEJE, Recife - PE.

${ }^{28}$ Cf. REGULAMENTOORGÂNICO DA ADMINISTRAÇÃO DO ENSINO PÚBLICO. Ano de 1879, p. 0152, APEJE, Recife-PE.

${ }^{29}$ APEJE: Série Instrução Pública IP 12 - 1860, p. 22.

${ }^{30}$ APEJE: Série Instrução Pública IP 13 - 1861, p. 10 (F e V).

31 Segundo o parágrafo $3^{\circ}$ do artigo 66 da lei n. 369, de 14 de maio de 1855 , o professor deveria, em caso de impedimento no exercício da docência, informar ao delegado literário. O professor Maximiniano descumpria a referida legislação. APEJE: Série Instrução Pública IP 15 - 1863, p. 167 (F e V)

${ }^{32}$ APEJE: Série Instrução Pública IP 15 - 1863, p. 167 (F e V), 168 (F e V) e 169.

${ }^{33}$ APEJE: Série Instrução Pública IP 16- 1864, p. 321.

34 Encontrado na seção "Apontamentos do mês de outubro". In:FOLHINHA Católica. Recife: Typographia Commercial de Geraldo H. de Mira \& C, 1862.Arquivo Público Estadual Jordão Emerenciano, Biblioteca. Recife - PE, p. 169.

\section{Referências Bibliográficas}

AZEVEDO, Elciene et al. Trabalhadores na cidade: cotidiano e cultura no Rio de Janeiro e em São Paulo. Campinas, SP: Editora da Unicamp, 2009.

Cultura associativa no Rio de Janeiro da Primeira República. In.

Fernando Teixeira da. FORTES, Alexandre (orgs.). Culturas de classe: identidade $e$ diversidade na formação do operariado. Campinas, SP: Editora da Unicamp, 2004. Pp: 95120.

CARVALHO, José Murilo de. Cidadania no Brasil: o longo caminho. 3ed. Rio de Janeiro: Civilização Brasileira, 2002.

EISENBERG, Peter. Modernização sem mudança: a indústria açucareira em Pernambuco: 1840-1910. São Paulo: Paz e Terra, 1977.

GARCIA, Inára. O "Ensino Público": discurso e prática na formação de professores para o século XIX. Anais do II CONGRESSO LUSO-BRASILEIRO DE HISTÓRIA DA EDUCAÇÃO, Portugal, Évora, 4 a 9 de abril de 2004.

GONDRA, José Gonçalves \& SCHUELER, Alessandra. Educação, poder e sociedade no Império Brasileiro. São Paulo: Cortez, 2008. 
GRAHAM, Richard. Clientelismo e Política no Século XIX. Rio de Janeiro, UFRJ, 1997.

HOBSBAWM, Eric J. Era dos Extremos: o breve século XX: 1914-1991. São Paulo: Companhia das Letras, 1995.

LIMA, Dayana Raquel Pereira de. Sinais do "desconforto" no exercício da docência pública em Recife e Olinda (1860-1880). 2014. 176f. Dissertação (Mestrado em Educação) Programa de Pós-Graduação em Educação, Universidade Federal de Pernambuco (UFPE), Recife, 2014.

MAC CORD, Marcelo. Artífices da cidadania: mutualismo, educação e trabalho no Recife oitocentista. Campinas, SP: Editora da Unicamp, 2012.

MAC CORD, Marcelo. BATALHA, Claudio H. M. Organizar e proteger: trabalhadores, associações e mutualismo no Brasil (séculos XIX e XX). Campinas, SP: Editora da Unicamp, 2014.

NÓVOA, Antônio. (Org.). Vidas de professores. $2^{\mathrm{a}}$ ed., Porto, Porto Editora, 2000.

Formação de professores e profissão docente. Ano de 1992. Disponível em http://repositorio.ul.pt/bitstream/10451/4758/1/FPPD_A_Novoa.pdf. Último acesso em agosto de 2013.

REVEL, Jacques. "Microanálise e construção do social". In. . Jogos de escalas: a experiência da microanálise. Rio de Janeiro, Fundação Getúlio Vargas, 1996, p. 15-38.

SANTOS, Yan Soares. A sociedade propaganda da instrução pública e suas ações de qualificação profissional em Recife (1872-1903). Recife: UFPE, 2014 (Dissertação de Mestrado em Educação).

SCHUELER, Alessandra Frota Martinez de. Culturas escolares e experiências docentes na cidade do Rio de Janeiro (1854-1889). 2002. 280 f. Tese (Doutorado em Educação) Programa de Pós-Graduação da Universidade Federal Fluminense (UFF), Niterói, 2002.

SILVA, Adriana Maria Paulo da. Processos de construção das práticas de escolarização em Pernambuco, em fins do século XVIII e primeira metade do século XIX. Recife: Editora Universitária da UFPE, 2006.

O trabalho docente em Recife e Olinda (1851-1890). Relatório de Pesquisa, Recife: FACEPE/CNPq/ UFPE, 2014.

SILVA, Fernando Teixeira da. Operário sem patrões: os trabalhadores da cidade de Santos no entreguerras. Campinas, SP: Editora da UNICAMP, 2003.

SOUZA, Felipe Azevedo e. Direitos políticos em depuração: A Lei Saraiva e o eleitorado do Recife entre as décadas de 1870 e 1880. 2012. 234f. Dissertação (Mestrado em História) Programa de Pós-Graduação da Universidade Federal de Pernambuco (UFPE), Recife, 2012.

TARDIF, Maurice \& LESSARD, Claude. Ofício de Professor. História, perspectivas e desafios internacionais. Petrópolis: Vozes, 2008.

THOMPSON, Edward P. A formação da classe operária. Vls.1, 2, 3. Rio de Janeiro: Paz e Terra, 1987 a, b e c.

VILLELA, Heloisa de O. S. O mestre-escola e a professora. In. LOPES, Eliane Marta Teixeira; FILHO, Luciano Mendes de Faria; VEIGA, Cynthia Greive. 500 anos de educação no Brasil. Belo Horizonte: Autêntica, 2000, p. 95-134. 